\title{
Estimação do Comércio Internacional Brasileiro em Clusters
}

\section{Estimation of Brazilian International Clusters Trade}

\author{
Júlio Vicente Cateia ${ }^{\mathrm{a}}$ \\ Édivo de Almeira Oliveira ${ }^{\mathrm{b}}$ \\ William Barbosa ${ }^{c}$
}

\begin{abstract}
Resumo: O objetivo deste estudo é investigar empiricamente o comércio internacional do Brasil com seus parceiros comerciais estimado por meio dos estimadores de máxima verossimilhança (MV), Poisson pseudo-maximum likelihood (PPML) e o sistema GMM em um modelo de comércio com bens contínuos. Analisa-se o desempenho das exportações brasileiras para os quatro clusters intercontinentais: o comércio Brasil-Mercosul, Brasil-Brics, Brasil-Zona do Euro e Brasil-Estados Unidos. Os estimadores MV e PPML reportam estimativas significativas e consistentes com a literatura gravitacional de que as rendas e populações dos países elevam o comércio, enquanto o custo de transporte mais alto tende a inibir os fluxos comerciais. A volatilidade cambial não se mostra um impeditivo ao comércio, ao menos no modelo estático. A fronteira não tem um importante papel na determinação do padrão do comércio entre o Brasil e seus parceiros regionais, sugerindo que os clusters intercontinentais podem ser fundamentais para os fluxos de exportações brasileiras, fato confirmado pelos resultados reportados pelo estimador do sistema GMM.
\end{abstract}

Palavras-chave: Comércio internacional. Modelo de Eaton e Kortum. Estimação por máxima verossimilhança. Estimador PPML. Sistema GMM.

\begin{abstract}
This study aims to empirically investigate Brazil's international trade with its commercial and political partners and the maximum likelihood (ML), Poisson PseudoMaximum Likelihood (PPML) and the GMM system estimators by estimating a trade model with continuous of goods. We investigated the performance of Brazilian exports to the four intercontinental clusters: Brazil-Mercosur, Brazil-Brics, Brazil-Euro zone and Brazil-United States trade. The ML and PPML estimators report significant and consistent estimates with the gravitational literature, that country incomes and populations contribute to increasing trade, while higher transport costs tend to inhibit trade flows. Exchange rate volatility does not prove to be an impediment to trade, at least in the static model. The border-effects does not play an important role in determining the pattern of trade between Brazil and its regional partners, suggesting that intercontinental

a Universidade Federal do Paraná (UFPR), Programa de Pós-Graduação em Desenvolvimento Econômico da Universidade Federal do Paraná (PPGDE). Curitiba, Paraná, Brasil.

b Universidade Estadual de Campinas (UNICAMP), Instituto de Economia (IE), Programa de Pós-Graduação em Economia. Campinas, São Paulo, Brasil.

c Universidade de São Paulo (USP), Escola Superior de Agricultura Luiz de Queiroz (ESALQ), Programa de Pós-Graduação em Economia Aplicada (PPGEA). Piracicaba, São Paulo, Brasil.
\end{abstract}


clusters may be essential to the Brazilian export flows, a fact confirmed by the results reported by the GMM system estimator.

Keywords: International trade. Model of Eaton and Kortum. Maximum likelihood. PPML estimators. GMM system.

JEL Classification: F14; Q11; Q17.

\section{Introdução}

Depois do tratado de Assunção no início da década de 1990, o comércio internacional brasileiro parece estar se movendo novamente, e não apenas para o antigo sistema de áreas regionais de livre-comércio, mas para um sistema de grandes agrupamentos intercontinentais que facilitam o intercâmbio de bens e serviços. Além da sua entrada nos mercados asiáticos, o Brasil, por razões políticas e comerciais, procurou se inserir tanto na Europa do Leste quanto na Ásia Meridional e no continente africano por meio do Brics (acrônimo de Brasil, Rússia, Índia, China e África do Sul). Atualmente, os quatro clusters (Brics, Estados Unidos, Mercosul e Zona do Euro) recebem 78\% das exportações brasileiras. Há indícios de que os clusters intercontinentais estão se tornando cada vez mais importantes para os fluxos das exportações brasileiras, deslocando a importância outrora atribuída ao Mercosul. Em 1997, a parcela das exportações brasileiras destinadas aos países que atualmente compõem o Rics (Rússia, Índia, China e África do Sul) era de cerca $2 \%$ das exportações totais, enquanto os fluxos de exportações destinadas para o Mercosul, Estados Unidos e a zona do Euro eram de 7\%, 7\% e 9\%, respectivamente, do total exportado naquele ano. Em 2011, as exportações brasileiras para o Rics subiram para 13\%, ao mesmo tempo que a parcela destinada para o Mercosul caiu para 7\%. A Zona do Euro e os Estados Unidos mantiveram suas percentagens anteriores. Em função do extraordinário crescimento da China e da Índia, o Brasil exportou para o Rics uma parcela de 10\% das exportações totais em 2016, que é superior às parcelas de 6\%, 7\% e 8\% exportadas para os Estados Unidos, Mercosul e Zona do Euro, respectivamente (IPEADATA, 2017; WORLD BANK, 2017).

O objetivo deste estudo é investigar empiricamente os determinantes do comércio internacional do Brasil com seus parceiros comerciais (Mercosul, Brics, Zona do Euro e Estados Unidos) e políticos (1989-2016) utilizando um modelo de comércio com bens contínuos estimados por máxima verossimilhança (MV), Poisson pseudo-maximum likelihood (PPML) e método de momentos generalizados (GMM). O estimador PPML foi desenvolvido para controlar a heterogeneidade persistente. Mais do que isso, a vantagem de se utilizar o estimador PPML no modelo de comércio internacional não decorre apenas do fato de permitir que 
se leve em conta a heterocedasticidade existente, mas também porque fornece estimativas não viesadas, mesmo na presença de muitos valores nulos na variável dependente, além de ser robusto à diferentes níveis de heterocedasticidade (SANTOS SILVA; TENREYRO, 2006). O sistema GMM é importante para esse propósito em função da endogeneidade presente em modelos gravitacionais, fornecendo estimativas que os estimadores tradicionais de modelos de painel estáticos não seriam capazes de reportar. O propósito é analisar se o esforço de inserção brasileira no Brics teria sido suficiente para reduzir a importância do Mercosul e se o efeito-fronteira ainda é importante para o atual padrão de comércio brasileiro. Procura-se testar a hipótese de que a fronteira pode não ter um importante papel na determinação do padrão do comércio entre o Brasil e seus parceiros regionais, bem como a noção de que os clusters intercontinentais podem ser fundamentais para os fluxos de exportações brasileiras.

Além desta introdução, o presente estudo está estruturado em mais cinco seções: segunda fornece uma revisão de literatura de modelos gravitacionais de comércio e suas aplicações; a terceira apresenta a evolução das relações comerciais entre o Brasil e os parceiros destacados anteriormente; a quarta descreve o modelo empírico, a base de dados e a estratégia de estimação empregada; a quinta apresenta as principais inferências obtidas; e, por fim, a sexta traça as considerações finais.

\section{Modelos Gravitacionais: uma Revisão de Literatura}

Em seu estudo seminal, Tinbergen (1962) aplica a equação gravitacional de Newton para a análise de fluxos de comércio, argumentando que os fatores que dificultam ou facilitam o comércio não devem se afastar das características principais dos países envolvidos. Do conjunto dos fatores que facilitam o comércio, alguns aspectos, como o tamanho dos mercados e a estrutura produtiva, eram tomados como centrais, pois havia um reconhecimento de que países com mercados amplos e de renda elevada necessitam ofertar ou comprar do exterior com maior frequência. Por outro lado, dentre os fatores que dificultam o comércio bilateral, destaca-se a distância entre os distintos países como a principal candidata a ensejar entraves aos fluxos comerciais internacionais. A formalização dessas ideias por Tinbergen (1962), tomando por base a equação de Newton, representa uma contribuição importante ao tradicional quadro teórico de Heckscher-Ohlin (YOTOV et al., 2016).

Dando continuidade ao estudo de Tinbergen, o trabalho de Geraci e Prewo (1977) mostra que, em equilíbrio, o comércio bilateral é influenciado por um conjunto mais amplo de variáveis, no qual as rendas brutas e componentes quantitativos (tarifas) e qualitativos (área de livre-comércio, passado histórico e língua 
comum) desempenham um papel fulcral. Aitken (1973) foi um dos pioneiros na utilização do modelo gravitacional padrão para investigar os determinantes de comércio bilateral. Inicialmente, os modelos gravitacionais receberam questionamentos dos economistas devido à carência de fundamentos microeconômicos. Tal ceticismo, porém, parece ter sido atenuado com o estudo de Anderson (1979), que forneceu os primeiros fundamentos microeconômicos com base nos pressupostos das teorias de estrutura de mercados perfeitos. Desde, então, o emprego desse tipo de modelo tem sido crescente.

Hamilton e Winters (1992) analisaram através do modelo de gravidade padrão o efeito da liberalização do comércio dos países do leste europeu e da União Soviética sobre o tamanho e a direção de fluxo de comércio dos países dessa região com países da Europa Ocidental e os Estados Unidos. Os autores concluíram que a abertura econômica desempenha papel importante no desenvolvimento econômico, pois tem o potencial de gerar renda, introduzir nova tecnologia e promover habilidades organizacionais, além de estimular a competição. Frankel et al. (1995) já haviam argumentado que, dentre os determinantes de comércio dentro da estrutura de um modelo gravitacional, a distância e o tamanho dos países são as variáveis que justificam a denominação dessa família de modelos na explicação do comércio bilateral.

MacCallum (1995) aplica o modelo de gravidade para um estudo de caso do impacto das fronteiras Canadá-Estados Unidos sobre os padrões de comércio regional, ou seja, visando avaliar o comércio entre as províncias do Canadá e entre estas com os estados dos Estados Unidos. Os dados utilizados são do ano de 1988 sobre importações e exportações de 10 províncias e 50 estados. Na equação, incluindo o comércio interprovincial com os estados americanos, MacCallum mostra que, variando a renda das províncias em 1\%, o comércio bilateral entre eles aumentaria em $1.21 \%$, ao passo que o impacto de variação de $1 \%$ na renda dos estados sobre o padrão de comércio é de $1.06 \%$ e da distância é -1.42\%. A conclusão é que as fronteiras continuam a desempenhar um papel central no padrão do comércio internacional.

Os chamados modelos de gravidade aumentados ou modelos de gravidade estendidos têm sido instrumentos importantes na avaliação do comércio desagregado (HATAB et al., 2010; ZHU; GU, 2008). Alguns desses modelos têm como base a equação de gravidade generalizada de Bergstrand (1985), derivada do modelo de equilíbrio geral walrasiano, e tornaram-se muitos úteis na avaliação do comércio de produtos agrícolas. Alguns estudos recentes avaliam o efeito dos clusters (ou bloco) sobre as exportações, incluindo o de Zarzoso e Lehmann (2003), que analisou o comércio Mercosul-União Europeia inferindo que câmbio, infraestrutura e diferenças de renda são variáveis importantes para a determinação de fluxos de comércio entre os dois blocos. 
Por sua vez, Bikker (2009) utilizou a equação de comércio padrão e a equação gravitacional aumentada para analisar o comércio de 178 países. Por meio dessas equações, encontrou estimativas significativas, com coeficientes positivos para dummy, renda e população do país exportador, mas negativos para distância e população do país importador. Esses resultados são similares àqueles reportados por El-Arisch (2012) para o comércio do Egito com a União Europeia e a Área de Livre-Comércio da África. No entanto, ao analisar o comércio bilateral do Paquistão, Khan, Haq e Khan (2013) encontraram estimativas significativas, com o coeficiente de rendas positivo, mas os coeficientes de distância e renda per capita e a dummy de fronteira foram negativos, um resultado que corrobora os obtidos por Mirian et al. (2013) ao analisarem o comércio da Turquia e outros países que exportam para o mesmo destino de suas exportações. Cafiso (2008) estimou o efeito-fronteira com o objetivo de entender o papel da União Europeia sobre o comércio intraeuropeu, tendo concluído que o efeito-fronteira não é relevante para explicar o comércio do bloco. Posteriormente, Cafiso (2011) mostra que o efeito-fronteira tende a concentrar a produção em economias abertas ao comércio. Recentemente, Bergstrand e Larch (2015) forneceram outras evidências que mostram os efeitos declinantes das fronteiras no comércio global.

Além desses estudos, Farias e Hidalgo (2012) também aplicaram a abordagem gravitacional para avaliar o comércio interestadual e o comércio internacional brasileiro, concluindo que a formação do Mercosul aumenta o comércio na região em detrimento do comércio com os demais parceiros. Por sua vez, Sá Porto (2002) avaliou o impacto do Mercosul nas regiões brasileiras utilizando o modelo gravitacional. Esse estudo aponta que os impactos mais significativos do Mercosul se deram, em maior medida, no Sul e Sudeste, o que poderia ser um indício para o agravamento das disparidades regionais no Brasil. Graf e Azevedo (2013) estimaram o fluxo potencial de comércio para os países do Mercosul utilizando o modelo gravitacional de dados em painel. Verificaram que o Brasil apresentou a maior parte dos fluxos bilaterais potenciais de comércio abaixo do previsto no caso de um comércio efetivo. Reis et al. (2014) investigaram se o regionalismo ou a formação de blocos econômicos implicou em criação ou desvio de comércio. Os principais resultados obtidos sugeriram que houve a criação do comércio e desvio de exportações no Mercosul.

Contudo, verifica-se uma carência de estudos nacionais que empreguem o modelo de Eaton e Kortum (2002) para fins de análise do comércio internacional entre a economia brasileira e seus parceiros. É um dado o fato de que o modelo de Eaton e Kortum tem sido amplamente aplicado pela literatura internacional. Por exemplo, Alvarez e Lucas Júnior (2007) investigaram, por meio do modelo de Eaton e Kortum, os determinantes da distribuição dos volumes do comércio (tais como tamanho, tarifas e distância) para mais de 60 economias e obtiveram resul- 
tados consistentes com a literatura gravitacional. Yang (2015) estimou o custo de comércio para 60 países em desenvolvimento utilizando o modelo de Eaton e Kortum, concluindo que os países em desenvolvimento estão sujeitos à distribuição de custos muito maiores e que as reduções nos custos podem resultar em grandes ganhos de comércio e de bem-estar social.

Assim, essa crescente diversidade de equações de gravidade não apenas confirma a flexibilidade e a ampla aplicabilidade dessa modelagem, mas também representa um certo avanço no sentido de encontrar outras variáveis que influenciam o comércio entre as nações e que permitem também investigar um conjunto mais amplo de questões relativas ao comércio bilateral.

\section{Evolução do Comércio entre os Parceiros Comerciais (1997-2018)}

Ao longo dos últimos 20 anos, o comércio internacional brasileiro passou por várias transformações. Essas mudanças perpassaram alterações nos principais parceiros comerciais brasileiros, bem como mudanças na composição da pauta exportadora. As exportações de produtos primários apresentaram altas taxas de crescimento durante a década de 2000 , passando a representar mais de 50\% do total de exportações no ano de 2010 (HIDALGO; FEISTEL 2013).

A Figura 1 apresenta os 12 principais parceiros do Brasil, que absorviam cerca de $65,97 \%$ das exportações brasileiras no ano de 1997. Apresenta também os 12 principais parceiros para o ano de 2018, cuja representatividade se mantém em cerca de $65,71 \%$. Como pode-se observar no ano de 1997, o principal parceiro comercial eram os Estados Unidos, importando do Brasil aproximadamente US\$ 9 bilhões FOB. Em segundo lugar, aparece a Argentina, com um pouco mais de US\$ 6 bilhões. Destaca-se que, nesse ano, a China ocupava a $12^{\circ}$ posição, com apenas US\$ 1 bilhão. 
Figura 1 - Exportações brasileiras para os 12 países principais parceiros comerciais nos anos de 1997 e 2018

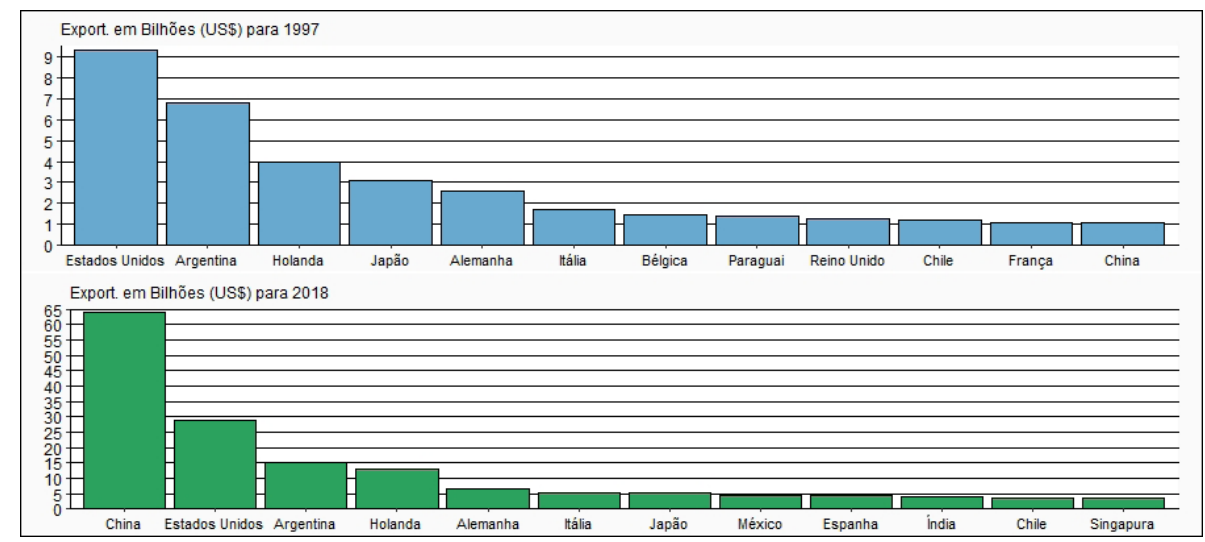

Fonte: Elaboração própria a partir de dados do COMEX STAT (2019).

Inicialmente, ao se comparar o primeiro gráfico com o segundo da Figura 1, constata-se que Bélgica, Paraguai, Reino Unido e França não estão mais presentes entre os 12 principais parceiros brasileiros enquanto destino das exportações, entrando nessa classificação México, Espanha, Índia e Cingapura, que representam um valor total de US $\$ 16,3$ bilhões e, aproximadamente, $6,8 \%$ do total das vendas externas brasileiras. Um fato importante a ser destacado é a posição da China nas exportações brasileiras, que, no ano de 2018, foi de US $\$ 64,02$ bilhões. Em termos percentuais, esse valor representou $26,76 \%$ das exportações nacionais, consagrando-se como principal parceiro comercial do Brasil.

Para prosseguir na análise, é importante verificar qual é o tipo de pauta importada do Brasil por cada país importador. A Figura 2 ilustra as exportações brasileiras para os 12 principais países de destinos, tanto para o ano de 1997 quanto para 2018, detalhados por tipo de produtos, quais sejam: produtos primários, ${ }^{1}$ produtos provenientes da indústria de transformação, extrativas e uma última categoria agregada denominada "outros produtos".

1 Essa categoria engloba os produtos da agricultura, pecuária, produção florestal, pesca e aquicultura. 
Figura 2 - Exportações brasileiras para os 12 países principais parceiros comerciais e sua composição em 1997 e 2018

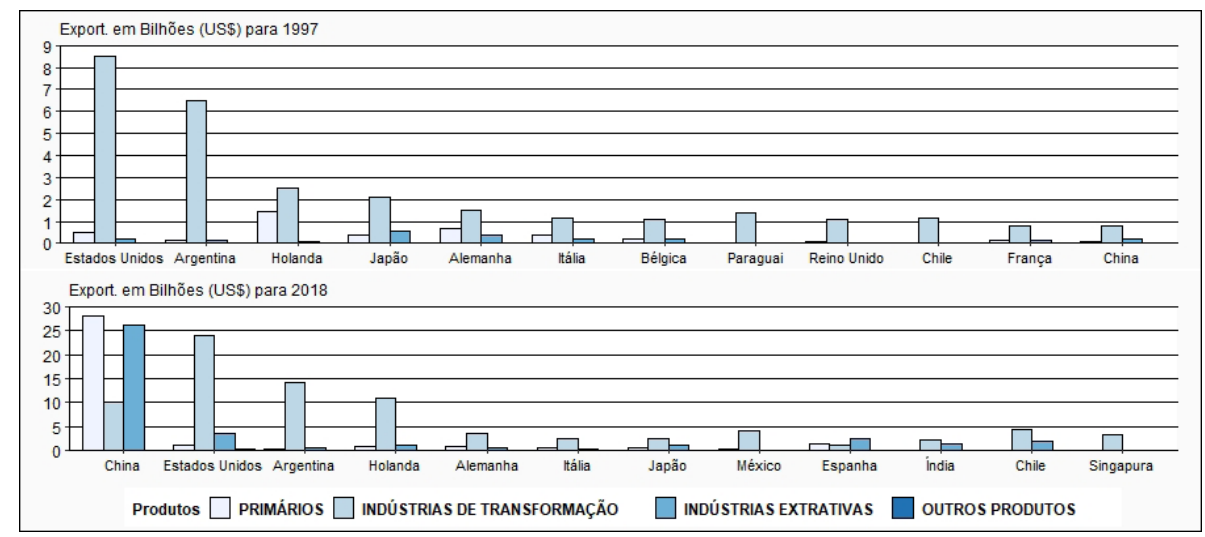

Fonte: Elaboração própria a partir de dados do COMEX STAT (2019).

De uma forma geral, com base na Figura 2, é possível perceber que o Brasil exportava, em 1997, essencialmente produtos da indústria de transformação, com destaque para os Estados Unidos e Argentina, que importavam, respectivamente, um montante de aproximadamente US\$ 8,5 e US\$ 6,4 bilhões da indústria de transformação brasileira. Para os demais países dessa lista, o Brasil exportava em torno de US\$ 1 bilhão em produtos manufaturados. Nesse ano, constata-se que a China importava do Brasil aproximadamente US\$ 0,8 bilhão em produtos manufaturados, o que representava cerca de 73,7\% do comércio entre os dois países. Quando se analisa o ano de 2018, constata-se a ocorrência de uma diversificação e elevação das exportações brasileiras. Concomitantemente, houve um aumento da dependência das exportações de produtos de baixo conteúdo tecnológico, sobretudo de commodities, bem como de produtos da indústria extrativa com destino à China, que se consolida como o principal comprador dessa categoria. Destaca-se, ainda a importância dos Estados Unidos, que importam aproximadamente US\$ 3,9 bilhões, sendo que esse valor representa 83,27\% do comércio entre as duas economias.

A Figura 3 apresenta a evolução das exportações para os destinos de interesse do presente estudo. Destaca-se que, em conjunto, no ano de 2018, esses foram o destino de $64,93 \%$ do total das vendas brasileiras. Constata-se que, em termos de volume de exportação, enquanto o mundo estava no auge da crise financeira de 2008, as exportações brasileiras para os demais países apresentaram redução significativa, exceto para os Brics, que continuaram em expansão até o ano de 2011, quando passam a experimentar tendência de declínio até 2016, mas retomando a tendência de expansão a partir de então. 
Figura 3 - Exportações brasileiras para os Estados Unidos, Brics, Mercosul e Zona do Euro $^{2}$ em 1997 e 2018

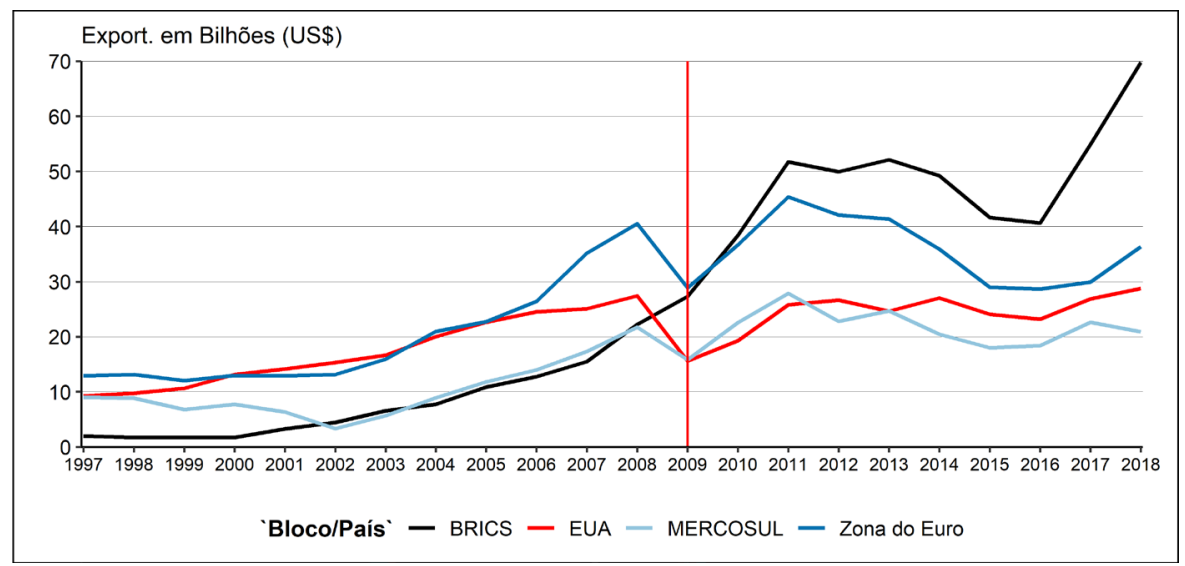

Fonte: Elaboração própria a partir de dados do COMEX STAT (2019).

Também é possível observar que houve uma retomada no crescimento das exportações brasileiras com destino aos Estados Unidos a partir de 2011 e, em período recente, também se observa certa retomada do crescimento entre 2016 e 2018. Tal recuperação foi o suficiente apenas para atingir o patamar observado antes da crise financeira de 2008 , com volume total de aproximadamente US $\$ 30$ bilhões. Destaca-se que, no conjunto de parceiros comerciais apresentados, os países do Mercosul apresentaram a maior expressividade em termos de volume nas exportações brasileiras. O fato é que, a despeito da relevância das exportações aos parceiros comerciais do Mercosul, a relação comercial do Brasil com esse bloco historicamente esteve bastante aquém da intensa atividade comercial estabelecida com a Zona do Euro e com o Brics, sobretudo após 2002.

Também é possível verificar uma reversão dos parceiros comerciais a partir de 2009, pois, de 1997 a 2008, os países da Zona do Euro e os Estados Unidos possuíam uma comercialização mais intensa, sendo que, a partir de 2008, em termos de volume exportado, os Brics ultrapassaram ambos países. Uma explicação plausível para esse fenômeno é que as exportações brasileiras destinadas a esse grupo de países é puxada, sobretudo, pela China, que é um país que apresentou maior taxa de crescimento econômico ao longo das últimas décadas, e como destacado anteriormente, importa em sua maioria produtos primários e da indústria extrativa.

2 Para a composição dos países, considerou-se a lista de 19 países no ano de 2019: Alemanha, Áustria, Bélgica, Chipre, Eslováquia, Eslovênia, Espanha, Estônia, Finlândia, França, Grécia, Irlanda, Itália, Letônia, Lituânia, Luxemburgo, Malta, Países Baixos (Holanda) e Portugal. Para maiores informações, ver: http://worldpopulationreview.com/countries/european-union-countries/ 


\section{Método}

Partindo-se de um modelo com tecnologia, preços e fluxos comerciais, de Eaton e Kortum (2002), com bens contínuos, a fração de bens que o país compra do país é também a fração de suas despesas com bens do próprio país:

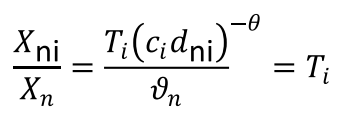

em que $X_{n}$ são gastos totais do país $n$ e $X_{n i}$ ã̃o gastos desse mesmo país com a produção oriunda do país i. A distribuição varia entre os países e o parâmetro específico de país, $T_{i}>0$, que governa a localização da distribuição. Um $T_{i}$ maior implica a possibilidade de um país se especializar na produção de um bem com mais eficiência. $T_{i}$ é, assim, um estado de tecnologia do país $i$ ou a sua vantagem em relação aos seus parceiros comerciais. $\theta>0$ é o parâmetro (comum para todos os países) que indica o montante de variação dentro da distribuição. Um $\theta$ maior implica menor variabilidade. O parâmetro $\theta$ regula a heterogeneidade entre os bens nas eficiências relativas dos países (EATON; KORTUM, 2002, p. 1747). A ideia é que um menor valor de gera maior heterogeneidade, significando que a vantagem comparativa exerce uma força maior para o comércio contra a resistência imposta pelas barreiras geográficas $d_{n i} \cdot c_{i}$, que é um custo de insumo.

O parâmetro $\vartheta_{n}$ contém informações muito importantes no modelo gravitacional. Ele traz informações relevantes como estados de tecnologia em todo o mundo, custos de insumos em todo o mundo e barreiras geográficas que governam os preços em cada economia. Portanto, o comércio internacional é capaz de ampliar o estado efetivo de tecnologia de cada economia com a tecnologia disponível de outras, descontada pelos custos de insumos e barreiras geográficas (EATON; KORTUM, 2002, p. 1748; BALDWIN; HARRIGAN, 2011).

Há duas possibilidades em termos de liberdade comercial. Em um extremo, considera-se um mundo de comércio gravitacional sem barreiras geográficas, isto é, $\forall d_{n i}=1$ para todo i e $n, \vartheta$ é o mesmo em todos os lugares e a lei do preço único valeria em tal situação para cada bem comercializável. No extremo oposto, há a autarquia com barrerias proibitivas, isto é, $d_{n i} \rightarrow \infty$ para $\forall i \neq n, \vartheta$ reduz-se apenas ao estado de tecnologia do país ponderado pelo seu custo de insumo, $T_{i} c_{i^{-}}$. As vendas do país exportador são representadas como:

$$
Q_{i}=\sum X_{\mathrm{mi}}=T_{i} c_{i^{-\theta}} \sum \frac{d_{\mathrm{mi}^{-\theta}} X_{m}}{\vartheta_{m}}
$$

Após algumas manipulações, como demonstrado por Eaton e Kortum (2002, p. 1750), a expressão 1 demonstra-se semelhante à equação gravitacional padrão, 
estabelecendo que o comércio bilateral está relacionado com as despesas do país importador e com as barreiras geográficas. Na verdade, resolvendo a equação 2 para $T_{i} c_{i^{-\theta}}$ e para todo índice de preço, tem-se:

$$
p_{j}=\gamma\left(\vartheta_{j^{-1}}^{-\frac{1}{\theta}}\right)
$$

Substituindo-se o resultado obtido na equação 1, tem-se uma representação gravitacional:

$$
X_{\mathrm{ni}}=\frac{T_{i}\left(d_{\mathrm{ni}} p_{n}\right)^{-\theta} X_{n}}{\sum\left(d_{\mathrm{mi}} p_{m}\right) X_{m}} Q_{i}
$$

na qual barreiras geográficas entre o país i e qualquer outro país importador é deflacionado pelo nível de preço do país importador $m$. A redução de $p_{m}$ opera da mesma maneira que uma barreira geográfica mais elevada: uma concorrência mais rígida no mercado $m$ reduz $p_{m}$, reduzindo o acesso do país $i$. As vendas totais do país exportador $Q_{i}$ e as compras do país importador $X_{n}$ entram com a elasticidade unitária. $O$ tamanho de mercado do país destinatário $m$ percebido pelo país $i$ é todo o termo $\left(d_{\mathrm{mi}} p_{m}\right) X_{m}$. Dado o estado de tecnologia, e assumindo a elasticidade de Armington unitária, o termo $\left(d_{\mathrm{ni}} p_{n}\right) X_{n}$ é o tamanho de mercado do país exportador $n$. Na perspectiva do país $i$, o denominador é o total do mercado mundial, de modo que a parcela do país $n$ nas vendas totais do país $i$ é apenas igual à parcela do país $n$ do mercado mundial efetivo de $i$. Na equação 4 , a sensibilidade do comércio aos custos e às barreiras geográficas depende do parâmetro tecnológico (refletindo a heterogeneidade dos bens na produção), ao invés de um parâmetro de preferência (refletindo a heterogeneidade dos bens no consumo). A ideia é que as partes envolvidas respondem por custos e barreiras geográficas na margem extensiva: à medida que uma fonte se torna mais cara ou remota, a exportação torna-se mais restritiva para uma gama de bens.

Nota-se que, se um país $i$ for capaz de abastecer um outro país $n$, a um custo relativamente mais baixo, então não haveria necessidade de $n$ demandar produtos de outros países, a exemplo de $m$. Para evitar quaisquer problemas dessa natureza, foram assumidas algumas preposições estabelecidas na literatura especializada em relação aos fluxos de comércio. ${ }^{3}$ A primeira é a independência de remessas ou decisões. As remessas se movem de forma mutuamente independentes, ou seja, uma exportação de $i$ para $j$ não afeta a probabilidade de ocorrência da outra exportação de i' para j', sendo a probabilidade das remessas $\left(R_{1}, \ldots, R_{N}\right)$ ir de i para $j$ definida por $P_{i j}$, cuja ocorrência também é independente dos valores das remessas.

3 Ver Savage e Deutsch (1960). 
Está implícito nessa premissa o argumento de que o comércio mundial é composto de muitas decisões por vários países produtores e diversos países consumidores e, portanto, as decisões dos produtores ou dos consumidores são homogêneas, visto que cada decisão individual envolve apenas uma pequena proporção do comércio total. Disso segue que as remessas $\mathrm{R}_{1}, \ldots, \mathrm{R}_{\mathrm{N}}$ são apenas as amostras aleatórias de população de possíveis remessas. A suposição para $\mathrm{R}$ é a mesma da estatística clássica, ou seja: a) todas as R's remessas são estatisticamente independentes; e b) a distribuição de R's tem valor médio finito, $\alpha$, e variância finita, $\sigma^{2}$. Outra premissa importante é a dependência em relação à origem e ao destino, ou seja, a noção de que uma remessa proveniente de um país em particular não afeta a probabilidade de outro país receber essa mesma remessa. No caso presente, os fatores que levam o Brasil a exportar para os demais países não interferem nas exportações dos mesmos produtos para outros mercados - desconsiderando-se a possibilidade de $\mathrm{o}$ Brasil (como o país remetente) receber suas próprias exportações.

\subsection{Modelo Econométrico Gravitacional}

O modelo gravitacional de painel à la Eaton e Kortum (2002) tem a seguinte forma estocástica:

$$
X_{\mathrm{ijt}}=T_{i j t} \beta+\lambda_{i}+\tau_{i}+\varepsilon_{i j t}
$$

em que $X_{\mathrm{it}}$ é a variável dependente do modelo, isto é, o volume de exportações anual; $T_{\mathrm{ijt}}=Y_{\mathrm{ijt}} N_{\mathrm{ijj}} C_{\mathrm{ijt}}$ Rat $t_{\mathrm{ij \textrm {j }}}$ é um vetor de variáveis explicativas estritamente exógenas, representando, respectivamente, rendas, populações, custos de comércio e volatilidade cambial; $\lambda_{i}$ são os efeitos fixos (EF) do país $i$; e $\tau_{i}$ são os $E F$ do período. A forma linear do modelo será:

$$
\ln X_{\mathrm{ijk}}=\alpha_{0}+\alpha_{1} \ln Y_{\mathrm{ijt}}+\alpha_{2} \ln N_{\mathrm{ijt}}+\alpha_{3} \ln C_{\mathrm{ijt}}+\alpha_{4} \operatorname{lnRat}_{\mathrm{ijt}}+\alpha_{5} \lambda_{i}+\alpha_{6} \tau_{i}+\ln \varepsilon_{\mathrm{ij}}
$$

Os testes usuais de Hausman, o teste de Chow e o teste de LM de Breusch-Pagan permitirão escolher o modelo econométrico mais adequado. Os estimadores MV e o estimador PPML, de Santos Silva e Tenreyro (2006), serão aplicados. Este estudo também emprega o estimador GMM desenvolvido por Arellano e Bover (1995) e Blundell e Bond (1998) para examinar a relação entre as exportações brasileiras e o custo de transporte, a volatilidade da taxa de câmbio, as rendas per capita e as populações dos seus parceiros comerciais. Para captar essa relação, um modelo gravitacional de painel dinâmico é especificado como segue: 


$$
X_{\mathrm{ijt}}=\alpha+\delta X_{i j t-1}+\beta Y_{i j t}+\sum \varphi_{m} Z_{\mathrm{mijt}}+\varepsilon_{i j t} ; j=1, . ., k ; i=1, \ldots . . n ; t=1, \ldots, T
$$

no qual $X_{\mathrm{ijt}}$ é a variável dependente do país no período ; $X_{\mathrm{ijt}-1}$ é a mesma variável defasada; $Y_{\mathrm{ijt}}$ representa as rendas dos $i$ e $j$ no tempo $t ; Z_{\text {miti }}$ denota todos os demais regressores incluídos no modelo como variáveis de controle para o país i; e $m$ indica o número de variáveis de controle incluídas. Um efeito fixo específico do país assumido para o termo de perturbação é:

$$
\varepsilon_{\mathrm{ijt}}=\tau_{i}+u_{i j t}
$$

em que $\tau_{i}$ representa os EF do país, que entram na expressão 7 como variáveis invariantes. Logo, $u_{\mathrm{ijt}}$ é assumido ser normalmente distribuído e estocasticamente independente, cujos momentos são $u_{\mathrm{ijt}} \approx\left(0, \sigma_{\mathrm{u}^{2}}\right)$. Um modelo de painel dinâmico, como na equação 7 , viola o pressuposto clássico de ortogonalidade, pois a variável dependente $X_{\mathrm{ijt}-1}$ depende de $\left.\varepsilon_{\mathrm{ijt}-1} \varepsilon_{\mathrm{ijt}}\right) \neq 0$, que é uma função de $\varepsilon_{\mathrm{ijt}}$. $\mathrm{Na}$ equação $8, \varepsilon_{\mathrm{ijt}}=\tau_{\mathrm{i}+} u_{\mathrm{ijt}}$, então $\mathrm{E}\left(X_{\mathrm{itt}-1}\right.$. Essa correlação sugere que a estimação de dados em painel dinâmicos sofre de viés que desaparece apenas à medida que $t \rightarrow \infty$. O problema pode, porém, ser superado simplesmente diferenciando-se a equação 7 como:

$$
\Delta \ln X_{\mathrm{ijt}}=\alpha+\delta \Delta \ln X_{\mathrm{ijt}-1}+\beta \Delta \ln Y_{\mathrm{ijt}}+\sum \varphi_{m} \Delta \ln Z_{\mathrm{mijt}}+\Delta u_{i j t}
$$

Entretanto, o termo de erro transformado $\Delta u_{i j t}$ é correlacionado com $\Delta \ln X_{\mathrm{ijt}-1}$, uma vez que ambos contêm $u_{\mathrm{ijt}-1}$. Como sugerido por Greene (2012) e Hsiao (2003), em painel estático o estimador OLS pode ser aplicado consistentemente. Contudo, o estimador OLS para dados em primeiras diferenças no modelo dinâmico gera estimativas de parâmetros inconsistentes. Vale notar que, na equação 9, $E\left(X_{\mathrm{ijt}-h} \Delta u_{i j t}\right)=0$ para $\forall h \geq 2, t=3, \ldots, T$

Esse resultado fornece informações particularmente interessantes para a estimação. A diferenciação das variáveis requer assumir um ponto inicial em que começa o processo gerador dos dados, já que a forma dos instrumentos (IV-variáveis instrumentais) válidos se torna inteiramente dependente da condição dos momentos, que permite identificar se os regressores são predeterminados ou se simplesmente são estritamente exógenos (ARELLANO; BOND, 1991; ARELLANO; BOVER, 1995). Anderson e Hsiao (1982) propuseram um estimador IV usando $\Delta \ln X_{\mathrm{ijt}-2}$ como instrumento, já que $E\left(X_{\mathrm{ijt}-2} \Delta u_{i j t}\right)=0$. 
Alonso-Borrego e Arellano (1996), Blundell e Bond (1998, p. 115) demonstraram que, em modelos de dados de painel dinâmico, cujo parâmetro autorregressivo é grande e o número de observações de séries temporais é moderadamente pequeno, o estimador de GMM linear tem um grande viés em amostras finitas e baixa precisão em estudos de simulação. Em tal situação, a variável dependente defasada é um instrumento fraco para as variáveis transformadas. Arellano e Bover (1995) apresentaram uma abordagem em que, para aumentar a eficiência do estimador, é necessário assumir a condição de momento $E\left(\Delta I_{i j t} \lambda_{i}\right)=0$ para todo $i$ e t. Assim, mesmo o estimador GMM exibindo o viés nas amostras finitas, comparativamente ao estimador OLS, ele é assintoticamente mais eficiente, pois o viés do OLS opera em direção contrária e de modo crescente (ARELLANO; BOND, 1991). O sistema de estimadores GMM é usado quando $N>T$ Um GMM dinâmico tem dois benefícios potenciais: a) resolve o problema de endogeneidade que nos modelos estáticos e estimador OLS não permite o uso de instrumentos internamente gerados (BOND, 2002; OSENI, 2016); b) todas as variáveis da equação não correlacionadas com o termo de erro podem ser usadas como instrumentos válidos (WOOLDRIDGE, 2002; BALTAGI, 2005; GREENE, 1993, 2012).

O teste de Sargan ou a estatística $J$ de Hansen têm sido amplamente utilizados para testar a restrição de sobreidentificação. Ademais, será empregado o teste de autocorrelação de Arellano-Bond para os erros na primeira diferença.

\subsection{Fonte e Tratamento de Dados}

As estatísticas descritivas das variáveis utilizadas são apresentadas na Tabela 1.

Tabela 1 - Estatísticas descritivas

\begin{tabular}{lccccc}
\hline $\begin{array}{l}\text { Estatísticas } \\
\text { descritivas }\end{array}$ & Observações & Média & $\begin{array}{l}\text { Desvio } \\
\text { padrão }\end{array}$ & Mínimo & Máximo \\
\hline $\mathrm{X}_{\mathrm{ij}}$ & 308 & 4492.808 & 3691.209 & 452.3894 & 16881.21 \\
$\mathrm{Y}_{\mathrm{ij}}$ & 308 & $1.77 \mathrm{e}+09$ & $3.18 \mathrm{e}+09$ & 2408807 & $2.27 \mathrm{e}+10$ \\
$\mathrm{~N}_{\mathrm{ij}}$ & 308 & $1.63 \mathrm{e}+07$ & $1.42 \mathrm{e}+07$ & 399492 & $4.87 \mathrm{e}+07$ \\
$\mathrm{C}_{\mathrm{ij}}$ & 308 & 2430.273 & 685.7736 & 1231 & 3238 \\
Rat $_{\mathrm{ij}}$ & 333 & 16.5567 & 685.7736 & 0 & 763.0271 \\
\hline
\end{tabular}

Fonte: Elaboração própria a partir dos dados da pesquisa.

Na Tabela 1, $\mathrm{X}_{\mathrm{ij}}$ denota os fluxos de exportações brasileiras para os seus parceiros comerciais (em US $\$$ milhões). O total de fluxo de exportações tem o seguinte formato (IPEADATA, 2017):

$$
X_{\mathrm{TOTAL}}=\sum \alpha_{j} X_{i} \quad i \neq j
$$


Destarte, é o total das exportações brasileiras e é o share de cada parceiro nas exportações totais. As variáveis independentes do modelo são:

a) $Y_{i j}$ : renda per capita dos parceiros comerciais do Brasil (em US\$ milhões) (WORLD BANK, 2017);

b) $\mathrm{N}_{\mathrm{i} i}$ : população dos parceiros comerciais do Brasil (em milhões) (WORLD BANK, 2017);

c) $C_{i j}$ : custo de transporte do comércio internacional brasileiro (distância em quilômetros). O cálculo da distância varia de estudo para estudo, então considerou-se a distância em quilômetros entre o Brasil e seus parceiros comerciais;

d) Rat $\mathrm{ij}_{\mathrm{ij}}$ v volatilidade cambial: volatilidade da taxa de câmbio comercial para venda (R\$/US\$) (IPEADATA, 2017);

e) efeito-fronteira: variável dummy que assume valor um para fronteira comum ou zero, caso contrário.

\section{Resultados e Discussões}

Esta seção tem por objetivo apresentar as estimativas e discutir os resultados dos modelos estáticos e dinâmicos representados pelas expressões 6 e 9. Os testes iniciais para a escolha do melhor modelo de painel estático, bem como o teste sobre autocorrelação foram realizados na primeira subseção a seguir. O objetivo é escolher o modelo mais adequado para estimar o efeito-fronteira. Nas três subseções seguintes, são reportadas as estimativas através de métodos de MV, PPML e GMM.

\subsection{Testes Preliminares}

Conforme a Tabela 2, a estatística calculada do teste de Chow é estatisticamente significativa aos níveis de significância convencionais (1\%, 5\% e 10\%), com $p$-valor zero, sugerindo que, levando-se em consideração as idiossincrasias dos países do Mercosul, o modelo de Efeitos Fixos (EF), que no caso é um estimador de Mínimos Quadrados Ordinários com Variáveis Dummies (MQOVD) parece ser o mais adequado. Pelo teste de Hausman não foi possível rejeitar a hipótese nula que o estimador de Efeitos Aleatórios (EA) é o mais indicado, ou seja, não se rejeitou a hipótese nula de que o modelo EA é melhor do que o de EF. Enquanto isso, o p-valor do teste LM é zero, sendo, assim, estatisticamente significante, levando à rejeição da hipótese nula, o que aponta para o modelo de EA em detrimento do modelo pooled. 
Tabela 2 - Testes preliminares para a escolha do modelo de dados em painel

\begin{tabular}{llllll}
\hline Teste & Modelo & Estimador & $\boldsymbol{P}$-valor & Estatística & $\begin{array}{l}\text { Critério de } \\
\text { decisão }\end{array}$ \\
\hline Chow & $\begin{array}{l}\text { Pooled } \\
\text { versus EF. }\end{array}$ & $\begin{array}{l}\text { MQO versus } \\
\text { MQOVD. }\end{array}$ & 0.000 & 36.871 & $\begin{array}{l}\text { Rejeita-se a } \\
\text { hipótese nula. }\end{array}$ \\
Hausman & $\begin{array}{l}\text { EA versus } \\
\text { EF. }\end{array}$ & $\begin{array}{l}\text { GLS versus } \\
\text { MQOVD. }\end{array}$ & 0.752 & - & $\begin{array}{l}\text { Não se rejeita a } \\
\text { hipótese nula. } \\
\text { Rreusch-Pagan } \\
\text { (LM) }\end{array}$ \\
$\begin{array}{l}\text { Pooled } \\
\text { Autocorrelação }\end{array}$ & $\begin{array}{l}\text { MQO versus } \\
\text { GLS. }\end{array}$ & 0.000 & 730.120 & $\begin{array}{l}\text { Reja-se a } \\
\text { hipótese nula. } \\
\text { Rejeita-se a } \\
\text { hipótese nula. }\end{array}$ \\
\hline
\end{tabular}

Fonte: Elaboração própria a partir de resultados da pesquisa.

Vale observar que o estimador de Hausman e Taylor (HT) tem sido empregado na literatura empírica de comércio ${ }^{4}$ porque se ajusta melhor aos modelos de comércio quando uma variável explicativa é correlacionada com o termo de erro e também na presença de heterogeneidade não observada. De acordo com Baltagi (2005), o estimador HT converge para o estimador de EA se o teste padrão de Hausman baseado no EF versus EA não for rejeitado, como mostrado na Tabela 2. Portanto, os testes realizados forneceram resultados em termos de qual é o melhor modelo a se utilizar e o estimador correspondente. Identificou-se que o modelo de EA é o mais adequado. Ademais, a estatística calculada de Wooldridge é significativa aos níveis de significância convencionais, com um p-valor zero, permitindo a rejeição da hipótese nula de ausência de autocorrelação de primeira ordem nos resíduos. Eventuais problemas de heterocedasticidade são corrigidos mediante erros padrões robustos com a correção da heterocedasticidade de White (White robust).

\subsection{Efeito-Fronteira: Estimação por Máxima Verossimilhança e Pseudo-Maximum Likelihood}

Os testes anteriores foram realizados com a finalidade de encontrar o modelo mais adequado para análise de efeito-fronteira, uma questão extremamente importante na discussão de políticas comerciais, pois a criação dos blocos econômicos regionais e muitos outros acordos bilaterais de comércio parecem não superar os custos de comércio impostos pelas fronteiras. O propósito aqui é verificar empiricamente se a fronteira ainda desempenha um papel crucial no comércio brasileiro.

A Tabela 3 reporta as estimativas da equação de comércio bilateral do Brasil com os países do Mercosul ao se aplicarem os métodos MV (segunda coluna) e

4 Ver Egger (2002), Egger e Pfaffermayr (2004), Egger (2005) e Carrere (2005). 
PPML (terceira coluna). Para fluxos de comércio com poucas observações nulas, como o caso do painel utilizado neste estudo, o estimador MV reportou estimativas maiores em magnitude comparativamente ao PPML. A diferença entre os coeficientes estimados por ambos os métodos de estimação é reportada na quarta coluna. Porém, o PPML gera estimativas estatisticamente significativas para todos os coeficientes, bem como um maior poder explicativo (um $R$-quadrado mais elevado).

Tabela 3 - Estimativas do modelo de painel estático para as exportações brasileiras para os principais parceiros comerciais de 1989 a 2016

\begin{tabular}{|l|l|l|c|}
\hline Estimativas/estimador & \multicolumn{1}{|c|}{ MV } & PPML & MV-PPML \\
\hline $\mathrm{Y}_{\mathrm{ij}}$ & $\begin{array}{l}1,0769 \\
(0,0981)^{* * *}\end{array}$ & $\begin{array}{l}0,06851 \\
(0,0017)^{* * *}\end{array}$ & 1,0083 \\
\hline $\mathrm{N}_{\mathrm{ij}}$ & $\begin{array}{l}1,1793 \\
(0,9219)^{* * *}\end{array}$ & $\begin{array}{l}0,05931 \\
(0,0013)^{* * *}\end{array}$ & 1,1199 \\
\hline $\mathrm{C}_{\mathrm{ij}}$ & $\begin{array}{l}-2,7825 \\
(0,4022)^{* * *}\end{array}$ & $\begin{array}{l}-0,1565 \\
(0,0046)^{* * *}\end{array}$ & $-2,626$ \\
\hline Rat $_{\mathrm{ij}}$ & $\begin{array}{l}0,0237 \\
(0,0302)\end{array}$ & $\begin{array}{l}0,0025 \\
(0,0013)^{* * *}\end{array}$ & 0,0212 \\
\hline Efeito-fronteira & $\begin{array}{l}-0,49621 \\
(0,2952)^{*}\end{array}$ & $\begin{array}{l}-0,02981 \\
(0,0032)^{* * *}\end{array}$ & $-0,4664$ \\
\hline$\alpha_{0}$ & $\begin{array}{l}14,4436 \\
(3,1932)^{* * * *}\end{array}$ & $\begin{array}{l}2,7251 \\
(0,03543)^{* * *}\end{array}$ & 11,7185 \\
\hline$R_{2}$ & 0,9314 & 0,9442 & \\
\hline $\mathrm{N}$ & 302 & 302 & \\
\hline
\end{tabular}

Fonte: Elaboração própria a partir de resultados da pesquisa.

Nota: Erros padrões entre parênteses; * $\mathrm{p}<0,10 ;{ }^{* *} \mathrm{p}<0,05$; e *** $\mathrm{p}<0,01$.

De uma forma geral, destaca-se que os três estimadores reportaram os mesmos sinais, mudando somente a magnitude de determinadas variáveis sobre as exportações. Na sequência, a discussão seguirá os resultados fornecidos pelo PPML. Os regressores em conjunto têm um alto poder de explicar a variável dependente, com um $R$-quadrado de 0.94 , ou seja, $94 \%$ das exportações brasileiras para o Mercosul são explicadas pela renda per capita, população do bloco, custo de comércio, volatilidade cambial e efeito-fronteira.

Todos os coeficientes estimados pelo PPML são estatisticamente significativos, com os sinais consistentes com a literatura de comércio internacional por meio da metodologia de modelos gravitacionais. Um crescimento em $1 \%$ da população e da renda per capita dos países do Mercosul está associado a um aumento do comércio brasileiro, respectivamente, em $0.06 \%$ e $0.07 \%$. A volatilidade cambial não é um impeditivo de comércio, sendo seu efeito positivo e estatisticamente significativo ao nível de $1 \%$, enquanto uma variação do custo de comércio em $1 \%$ associa-se a uma redução de $0.16 \%$ no comércio brasileiro e seus parceiros comerciais. 
De acordo com as estimativas reportadas, o efeito-fronteira não apresentou papel na determinação do padrão do comércio entre o Brasil e seus parceiros regionais. Dados os demais fatores, o resultado confirma essa hipótese, indicando que o efeito-fronteira sobre as exportações, embora estatisticamente significativo a $1 \%$, é de $-0.03 \%$. Pode-se argumentar que esse fato não corrobora o estudo seminal de MacCallum (1995), o qual discute os impactos das fronteiras Canadá-Estados Unidos sobre os padrões de comércio. Para o autor, apesar das crescentes formações de blocos econômicos e de acordos de comércio, as fronteiras continuam desempenhando papel importante na determinação dos fluxos comerciais, afirmação também defendida por Helliwell (1997). Este autor mostra que, em função da existência de efeito-fronteira, o comércio interprovincial do Canadá, no período entre 1988 e 1990, é 20 vezes mais denso que o comércio entre províncias dessa economia com os estados americanos.

No entanto, o resultado aqui reportado está de acordo com a literatura recente analisando o comércio de um país com o bloco econômico a que pertence (HEAD; MAYER, 2000). De acordo com essa literatura, o comércio regional pode ser viesado, e esse viés é explicado pelas existências de barreiras nacionais ao comércio, quais sejam regulamentos alfandegários, obstáculos linguísticos, etc. (WOLF, 1997). Como resultado, ainda que a fronteira seja importante para determinar o comércio bilateral (Brasil-Agentina, por exemplo), o comércio brasileiro com o bloco pode ser predominantemente explicado por outros fatores (rendas, populações, outros), tendo a fronteira um papel secundário.

\subsection{Estimação do Comércio Bilateral Brasileiro: Método Poisson Pseudo-Maximum Likelihood}

Através do método de estimação proposto por Santos e Tenreyro (2006), o PPML, as estimativas do modelo gravitacional de Eaton e Kortum, representado pela equação 6, estão reportados na Tabela 4. As estimativas para a equação do comércio brasileiro com os demais países do Mercosul, do Rics, da Zona do Euro e com os Estados Unidos estão reportados na segunda, terceira, quarta e quinta colunas, respectivamente.

Tabela 4 - Estimativas do modelo de painel estático para as exportações brasileiras para parceiros: blocos comerciais de 1989 a 2016

\begin{tabular}{llllc}
\hline $\begin{array}{l}\text { Estimativas/ } \\
\text { estimador }\end{array}$ & $\begin{array}{c}\text { PPML } \\
\text { (Mercosul) }\end{array}$ & \multicolumn{1}{c}{$\begin{array}{c}\text { PPML } \\
\text { (Rics) }\end{array}$} & $\begin{array}{c}\text { PPML } \\
\text { (Zona do Euro) }\end{array}$ & $\begin{array}{c}\text { PPML } \\
\text { (Estados Unidos) }\end{array}$ \\
\hline $\mathrm{Y}_{\mathrm{ij}}$ & 0,0684 & 0,7016 & 0,0593 & 0,0372 \\
& $(0,0018)^{* * *}$ & $(0,0035)^{* * *}$ & $(0,0342)^{* *}$ & $(0,0158)^{* *}$ \\
$\mathrm{~N}_{\mathrm{ij}}$ & 0,0588 & 0,0638 & 0,7492 & $-0,0332$ \\
& $(0,0014)^{* * *}$ & $(0,0063)^{* * *}$ & $(0,1552)^{* * *}$ & $(0,1106)$ \\
\hline
\end{tabular}

Continua... 
Conclusão.

\begin{tabular}{lllll}
\hline $\begin{array}{l}\text { Estimativas/ } \\
\text { estimador }\end{array}$ & $\begin{array}{c}\text { PPML } \\
\text { (Mercosul) }\end{array}$ & $\begin{array}{c}\text { PPML } \\
\text { (Rics) }\end{array}$ & $\begin{array}{c}\text { PPML } \\
\text { (Zona do Euro) }\end{array}$ & $\begin{array}{c}\text { PPML } \\
\text { (Estados Unidos) }\end{array}$ \\
\hline $\mathrm{C}_{\mathrm{ij}}$ & $-0,1405$ & $-0,0980$ & & \\
& $(0,0045)^{* * *}$ & $(0,0284)^{* * *}$ & & \\
Rat $_{i j}$ & 0,0022 & 0,0083 & 0,0033 & $-0,0006$ \\
& $(0,0014)$ & $(0,0026)^{* * *}$ & $(0,0010)^{* * *}$ & $(0,0010)$ \\
$\alpha_{0}$ & 2,5858 & 2,1668 & 13,4893 & 3,4407 \\
& $(2,812)^{* * *}$ & $(0,1536)^{* * *}$ & $(0,5311)^{* * *}$ & $(1,9834)^{*}$ \\
\hline$R^{2}$ & 0,9342 & 0,8528 & 0,9403 & 0,8943 \\
$N$ & 302 & 106 & 25 & 35 \\
\hline
\end{tabular}

Fonte: Elaboração própria a partir de resultados da pesquisa.

Nota: Erros padrões entre parênteses; * $\mathrm{p}<0,10 ;{ }^{* *} \mathrm{p}<0,05$; e ** $\mathrm{p}<0,01$.

Os coeficientes estimados para a renda per capita, população e custo de transporte na segunda coluna (países do Mercosul) são estatisticamente significativos ao nível de significância de 1\%, sendo que o aumento de $10 \%$ na renda dos países do Mercosul está associado ao aumento das exportações brasileiras para esses países em \%, por outro lado, o mesmo aumento de $10 \%$ na população dos países do Mercosul, verifica-se a um incremento de nas exportações. A variação do custo de transporte internacional dos produtos do Brasil em 10\% tem o impacto de aproximadamente nas exportações brasileiras para o Mercosul, enquanto o efeito da volatilidade cambial no fluxo de exportação não foi estatisticamente significativo.

O resultado da terceira coluna obtido para os países do Brics mostra que todos os coeficientes são estatisticamente significativos a $1 \%$. O aumento de $10 \%$ na renda per capita desses países é significativamente associado a um aumento de nas exportações, consistente com as magnitudes obtidas por Zhu e Gu (2008). Com base nos resultados dos autores, supondo um aumento em $10 \%$ nas rendas externas, as exportações chinesas aumentam em . Com relação a mesma variação no tamanho da população e à volatilidade cambial, os aumentos associados são de, aproximadamente, e respectivamente. Um aumento do custo de transporte teria como resultado a diminuição das exportações brasileiras em aproximadamente $0.98 \%$

Todas as estimativas do modelo de comércio brasileiro com a Zona do Euro (quarta coluna) foram significativas a $5 \%$, exceto o coeficiente da renda per capita, que apenas foi significativo a $10 \%$. A variação da renda per capita dos países da Zona do Euro em 10\% se associaria a um aumento de apenas do volume de comércio, que, por sua vez, um crescimento da população na mesma proporção resultaria no incremento de nesse volume. Por conseguinte, para os comércios Brasil-Mercosul e Brasil-Brics, o coeficiente da volatilidade cambial para a equação de comércio do Brasil com a Zona do Euro também é positivo, porém com um impacto extremamente baixo, aumentando apenas do fluxo de comércio bilateral. 
Por fim, a quinta coluna apresenta as estimativas para o comércio bilateral Brasil-Estados Unidos. Com base nos resultados, o impacto da renda per capita sobre o volume de comércio brasileiro para os Estados Unidos é de, estatisticamente significativo a 5\%. O custo de transporte representado pela distância apresenta a colinearidade e foi computacionalmente excluído no processo de estimação, assim como foi feito para o caso da expressão representando o comércio Brasil-Zona do Euro. Ademais, essas variáveis no modelo não foram significativas do ponto de vista estatístico. Além disso, o coeficiente da população não é consistente com a literatura gravitacional de que o tamanho de mercado representado pela população seria um fator atrator de comércio. Entretanto, esse sinal corrobora a afirmação de Farias e Hidalgo (2012) de que uma população grande do país exportador desenvolvido tem o consumo mais diversificado e demanda relativamente uma fração menor de bens produzidos no exterior do que a população de pequenos países insulares, cuja demanda externa é limitada às necessidades básicas.

Para eliminar os efeitos específicos de tempo dos países considerados na amostra e da possível endogeneidade comumente presente em modelos gravitacionais de comércio, procedeu-se com a estimação de painel dinâmico, especificamente, aplicando-se o estimador GMM desenvolvido por Arellano e Bover (1995) e Blundell e Bond (1998) para examinar o comércio internacional brasileiro, cujas estimativas se encontram na Tabela 5. As duas equações representando o comércio Brasil-Zona do Euro e Brasil-Estados Unidos foram excluídas, uma vez que há somente um grupo para cada expressão. Portanto, foram estimadas somente as equações de comércio Brasil-Mercosul e Brasil-Brics, segunda e terceira colunas, respectivamente, da Tabela 5.

Tabela 5 - Estimativas do painel dinâmico GMM para as exportações brasileiras para parceiros dos blocos comerciais de 1989 a 2016

\begin{tabular}{lllll}
\hline Estimativas/estimador & $\begin{array}{c}\text { GMM } \\
\text { (Mercosul) }\end{array}$ & $\begin{array}{c}\text { GMM } \\
\text { (Brics) }\end{array}$ & $\begin{array}{c}\text { GMM- } \\
\text {-PPML }\end{array}$ & $\begin{array}{c}\text { GMM- } \\
\text {-PPML }\end{array}$ \\
\hline $\mathrm{Y}_{\mathrm{ij}}$ & 0,3112 & 0,4015 & & \\
& $(0,0882)^{* * *}$ & $(0,1388)^{* * *}$ & 0,2428 & $-0,3001$ \\
$\mathrm{~N}_{\mathrm{ij}}$ & 0,4513 & 0,3171 & & \\
& $(0,0936)^{* * *}$ & $(0,15661)^{* * *}$ & 0,3925 & 0,2533 \\
$\mathrm{C}_{\mathrm{ij}}$ & $-0,5543$ & $-0,04690$ & & \\
& $(0,2999)^{*}$ & $(0,4657)$ & $-0,4138$ & 0,0511 \\
Rat $_{\mathrm{ij}}$ & 0,0354 & $(0,3599)$ & & \\
& $(0,0255)$ & $-2,1105$ & 0,0332 & 0,0431 \\
$\alpha_{0}$ & 0,5104 & $-2,1105$ & & \\
& $(1,8000)$ & $(3,0889)^{* * *}$ & $-2,0754$ & 4,2773
\end{tabular}

Continua... 
Conclusão.

\begin{tabular}{|c|c|c|c|c|}
\hline Estimativas/estimador & $\begin{array}{c}\text { GMM } \\
\text { (Mercosul) }\end{array}$ & $\begin{array}{c}\text { GMM } \\
\text { (Brics) }\end{array}$ & $\begin{array}{l}\text { GMM- } \\
\text {-PPML }\end{array}$ & $\begin{array}{l}\text { GMM- } \\
\text {-PPML }\end{array}$ \\
\hline L1. & $\begin{array}{l}0,8136 \\
(0,0624)^{* * *}\end{array}$ & $\begin{array}{l}0,4445 \\
(0,0942)^{* * * *}\end{array}$ & & \\
\hline L2. & $\begin{array}{l}-0,1107 \\
(0,0464) * * *\end{array}$ & $\begin{array}{l}0,2375 \\
(0,0682)^{* * *}\end{array}$ & & \\
\hline $\mathrm{N}$ & 280 & 106 & & \\
\hline Número de grupos & 11 & 4 & & \\
\hline Números de instrumentos & 80 & 80 & & \\
\hline Valor $p$-Wald & 0,000 & 0,000 & & \\
\hline $\begin{array}{l}\text { Teste de Sargan } \\
\text { de restrições de } \\
\text { sobreidentificação ( } p \text {-valor) }\end{array}$ & 0,000 & 0,000 & & \\
\hline $\begin{array}{l}\text { Teste de Arellano-Bond de } \\
\text { autocorrelação } \\
(\text { Prob > z) }\end{array}$ & 0,018 & 0,0661 & & \\
\hline
\end{tabular}

Fonte: Elaboração própria a partir de dados da pesquisa.

Nota: Erros padrões entre parênteses; * $\mathrm{p}<0,10 ;{ }^{* *} \mathrm{p}<0,05$; $\mathrm{e}^{* * *} \mathrm{p}<0,01$; a quarta e a quinta colunas são resultado da diferença entre as estimativas reportadas pelo estimador GMM em comparação ao estimador PPML, isto é, tomando-se como exemplo: a segunda coluna da Tabela 5 menos a segunda coluna da Tabela 4 resultam na quarta coluna da Tabela 5, e a mesma lógica se aplica à última coluna.

Na segunda coluna da Tabela 5, as estimativas da renda per capita do Mercosul foram estatisticamente significativas a $1 \%$ e com sinal positivo, indicando uma relação positiva do tamanho da renda per capita em relação ao aumento do fluxo das exportações brasileiras. Por conseguinte, um crescimento de 1\% da população dos países do Mercosul está associado ao aumento das exportações brasileiras para o Mercosul em, sendo estatisticamente significativo ao nível de 1\%. Por outro lado, as estimativas de custo de transporte indicam que há uma redução de se a distância aumenta em $1 \%$. Por fim, constata-se que a volatilidade cambial não foi estatisticamente significativa considerando-se os níveis de significância convencionais.

As principais alterações em relação aos modelos estáticos ocorreram tanto em termos da magnitude quanto também em termos de significância estatística dos parâmetros estimados. Essas diferenças estão apresentadas na quarta e quinta colunas da Tabela 5, reportando a mudança relativa na magnitude dos coeficientes estimados para o comércio Brasil-Mercosul quando se aplica o sistema GMM. A quinta coluna da Tabela 5 reporta a diferença entre as estimativas mostradas na terceira coluna da mesma tabela e as estimativas da terceira coluna da Tabela 4, a fim de mostrar a mudança relativa da magnitude dos coeficientes estimados para o comércio Brasil-Brics quando aplicado o sistema GMM, ao invés do PPML. 
Alguns coeficientes aumentaram de magnitude, enquanto outros diminuíram. Na quarta coluna da Tabela 5 é possível observar que o coeficiente associado à renda per capita gerado através do GMM é 0.24 vezes maior que aquele resultante da estimação por PPML. Os respectivos coeficientes da população do Mercosul e da volatilidade cambial foram 0.40 e 0.03 vezes maiores do que os obtidos pelo método PPML, enquanto que a estimativa do parâmetro de custo do comércio brasileiro aumentou em 0.4138 vezes. Enquanto isso, a quinta coluna da mesma tabela mostra que, para a equação de comércio brasileiro com os países que atualmente compõem o Brics, as estimativas reportadas pelo GMM para os parâmetros de renda e custo de transporte diminuíram em magnitude, com magnitudes de e , respectivamente. Os demais coeficientes obtidos pelo GMM continuam sendo maiores do que aqueles reportados pelo PPML.

Esses resultados sugerem que um modelo gravitacional que segue a especificação de Eaton e Kortum (2002) e que considera uma amostra expressiva, o método de estimação GMM fornece melhores resultados comparativamente ao método PPML de Santos e Tenreyro (2006). Entretanto, em termos de sinais, os parâmetros continuam sendo estáveis e bastante consistentes com a literatura empírica de comércio gravitacional. Por exemplo, Paas (2000) comenta que as vantagens do uso da abordagem gravitacional decorrem da sua capacidade de explicar o padrão de comércio internacional nas condições de pouco volume de dados e sua validade teórica para diversos tipos de fluxos de exportações.

Os resultados obtidos aqui convergem tanto em sinais quanto em magnitudes dos parâmetros para os recentemente reportados pela literatura empírica de comércio, em particular aquela focando analisar os efeitos dos clusters e o efeito-fronteira. Bergstrand e Larch (2015) estimaram diferentes equações gravitacionais e encontraram resultados semelhantes, com a fronteira continuamente reduzindo seu papel em explicar o comércio. As estimativas estatísticas significativas de Cafiso (2011) sugerem também o papel das variáveis padrões, tais como rendas, na explicação do padrão do comércio, tendo mostrado que a fronteira pode explicar a concentração geográfica da produção. An e Puttitanun (2009) comentam que, na análise de comércio bilateral, é importante observar a magnitude e os sinais dos parâmetros, que, no presente estudo, corroboram a maioria da literatura revisada. Em particular, os parâmetros estimados para rendas, populações e custos de comércio são robustos.

\section{Considerações Finais}

Procurou-se testar se o esforço de inserção brasileira no Brics teria sido suficiente para reduzir a importância do Mercosul e se o efeito-fronteira ainda é importante para o atual padrão de comércio brasileiro. O modelo de Eaton Kortum é o mais adequado 
para esse propósito porque permite verificar se as partes envolvidas respondem por custos e barreiras geográficas na margem extensiva, isto é, se, à medida que uma fonte se torna mais cara ou remota, a exportação torna-se mais restritiva.

A criação dos blocos econômicos regionais e muitos outros acordos bilaterais de comércio parecem não superar os custos de comércio impostos pelas fronteiras. Investigou-se o efeito-fronteira aplicando-se os estimadores MV e PPML. Este reporta estimativas mais significativas e consistentes com a literatura gravitacional no sentido de que as rendas e populações dos países contribuem decisivamente para o estímulo do comércio, enquanto o custo de transporte mais elevado tende a inibir os fluxos comerciais. A volatilidade cambial não se mostra um impeditivo ao comércio, ao menos no modelo estático. A fronteira não tem um importante papel na determinação do padrão do comércio entre o Brasil e seus parceiros regionais, sugerindo a importância dos clusters intercontinentais para as exportações brasileiras. Assim, pode ser requerido um estudo incorporando as diferentes dimensões de fronteira (linguístico-cultural, gostos, etc.).

No presente estudo, essa discussão foi estendida considerando-se o comércio do Brasil com os quatro clusters internacionais: os comércios Brasil-Mercosul, Brasil-Brics, Brasil-Zona do Euro e Brasil-Estados Unidos. As estimativas reportadas pelo PPML sugerem que a expansão econômica desses clusters pode ser dinamicamente importante para as exportações brasileiras. Essa é uma matéria de política de inserção internacional relevante, uma vez que, à medida que o Brasil mantém a sua posição de uma das maiores economias da região latino-americana, a busca por novos parceiros comerciais em outros continentes, principalmente nos países cujas economias estão se expandindo, poderá significar uma estratégia eficiente de comércio.

O que se identificou neste estudo, tanto para as estimativas do modelo estático quanto para as estimativas reportadas pelo GMM, sugere a importância dos fatores externos na determinação das exportações brasileiras. O custo de transporte continua sendo um importante fator que restringe as exportações, enquanto a volatilidade cambial só é significativa nos comércios Brasil-Mercosul e Brasil-Rics.

\section{Referências}

AITKEN, N. D. The Effect of the EEC and EFTA on European Trade: A Temporal CrossSection Analysis. The American Economic Review, v. 5, p. 881-892, 1973.

ALONSO-BORREGO, C., ARELLANO, M. Symmetrically Normalised Instrumental Variable Estimation Using Panel Data. CEMFI Working Paper, n. 9612, 1996.

ALVAREZ, F.; LUCAS, JR., R. E. General equilibrium analysis of the Eaton-Kortum model of international trade. Journal of Monetary Economics, v.54, p. 1726-1768, 2007. 
AN, G.; PUTTITANUN, T. Revisiting McCallum's Border Puzzle. Economic Development Quarterly, v. 23, n. 2, p. 167-170, 2009.

ANDERSON, J. E. A theoretical foundation for the gravity equation. The American economic review, v. 69, n. 1, p. 106-116, 1979.

ANDERSON, T.W.; HSIAO, C. Formulation and estimation of dynamic models using panel data. Journal of Econometrics, v. 18, 47-82, 1982.

ARELlANO, M.; BOND, S. Some Tests of Specification for Panel Data: Monte Carlo Evidence and an Application to Employment Equations. The Review of Economic Studies, v. 58, n. 2, p. 277-297, 1991.

ARELLANO, M.; BOVER, O. Another look at the instrumental variable estimation of errorcomponents models. Journal of Econometrics, v. 68, p. 29-51, 1995.

BALDWIN, R.; HARRIGAN, J. Zeros, Quality, and Space: Trade Theory and Trade Evidence. American Economic Journal: Microeconomics, v. 3, p. 60-88, 2011.

BALTAGI, B. Econometric Analysis of Panel Data. 3. ed. Chichester: John Wiley E Sons, 2005.

BERGSTRAND, J. H. The Gravity Equation in International Trade: Some Microeconomic Foundations and Empirical Evidence. The Reviews of Economics and Statistics, v. 67, n. 4, p .474-481, 1985.

BERGSTRAND, J. H.; LARCH, M. Economic Integration Agreements, Border Effects, and Distance Elasticities in The Gravity Equation. European Economic Review, v. 78, p. 1-41, 2015.

BIKKER, J. A. An extended gravity model with substitution applied to international trade. Tjalling C. Koopmans Research Institute Discussion Paper Series, n. 215, 2009. Disponível em: http://www.uu.nl/sites/default/files/rebo_use_dp_2009_09-17.pdf. Acesso em: 12 fev. 2015.

BM. Banco Mundial. Disponível em: htp://data.worldbank.org/. Acesso em: 20 mar. 2017.

BLUNDELL, R.; BOND, S. Initial conditions and moment restrictions in dynamic panel data models. Journal of Econometrics, v. 87, p. 115-143, 1998.

BOND, S. Dynamic panel data models: a guide to microdata methods and practice. Portuguese Economic Journal, v. 1, p. 141-162, 2002.

CAFISO, G. The Euro's Influence Upon Trade Rose Effect Versus Border Effect. EBC Working Paper Series, n. 941, 2008.

CAFISO, G. Sectoral Border Effects and the Geographic Concentration of Production. Review of World Economics, v. 147, n. 3, p. 543-566, 2011.

COMEX STAT/MDIC. Plataforma de Consultas e Extrações de Dados Estatísticos do Comércio Exterior Brasileiro. Brasília, DF: Ministério do Desenvolvimento, Indústria e Comércio. 2019. Disponível em: < http://comexstat.mdic.gov.br/pt/geral>. Acesso em: 20 jul. 2018. 
EATON, J.; KORTUM, S. Technology, Geography, and Trade. Econometrica, v. 70, n. 5, p. 1741-1779, 2002.

EGGER, P. An Econometric View on the Estimation of Gravity Models and the Calculation of Trade Potentials. The World Economy, v. 29, n. 2, p. 297-312, 2002.

EGGER, P. Alternative Techniques for Estimation of Cross-Section Gravity Models. Review of International Economics, v. 13, n.5, p 881-891, 2005.

EGGER, P.; PFAFFERMAYR, M. Distance, Trade and FDI: A Hausman-Taylor SUR Approach. Journal of Applied Econometrics, v. 19, p. 227-246, 2004.

EL-ARISH, M. A. A Gravity Model Analysis of Egypt's Trade and Some Economic Blocks. In: NEJADKOORKI, F. International Conference on Applied Life Sciences. London: IntechOpen, 2012. p. 343-350. Disponível em: http://cdn.intechopen.com/pdfs-wm/39918.pdf. Acesso em: 21 abril 2015.

FARIAS, J. J.; HIDALGO, A. B. Comércio interestadual e comércio internacional das regiões brasileiras: Uma análise utilizando o modelo gravitacional. Documentos Técnico-Científicos, v. 43, n. 2 , p. 252-265, 2012.

FRANKEL, F.; STEIN, E.; WEI, S. Trading blocs and the Americas: The natural, the unnatural, and the super-natural. Journal of Development Economics, v. 47, p. 61-95, 1995.

GERACI, V. J.; PREWO, W. Bilateral Trade Flows and Transport Costs. The Review of Economics and Statistics, v. 59, n. 1, p. 67-74, 1977.

GRAF; C, O.; AZEVEDO, A. F. Z de. Comércio bilateral entre os países membros do Mercosul: uma visão do bloco através do modelo gravitacional. Economia Aplicada, v. 17, n. 1, p. 135-158, 2013.

GREENE, W. H. Econometric Analysis. New Jersey: Prentice HALL, 1993.

GREENE, W. H. Econometric Analysis. London: Pearson, 2012.

HAMILTON, C. B.; WINTERS, L. A. Opening Up International Trade in Eastern Europe. Stockholm International Economics Studies Papers, n. 511, 1992.HATAB, A. A.; ROMSTAD, E.; HUO, X. Determinants of Egyptian Agricultural Exports: A Gravity Model Approach. Modern Economic, v. 1, p. 134-143, 2010.

HELLIWELL, J. F. National Borders, Trade and Migration. Pacific Economic Review, v. 2, n. 3, p. 165-185, 1997.

HIDALGO, A. B.; FEISTEL, P. R. Mudanças na estrutura do comércio exterior brasileiro: uma análise sob a ótica da teoria de Hecksher-Ohlin. Estudos Econômicos, v. 43, n. 1, p. 79-108, 2013.

HSIAO, C. Analysis of Panel Data. New York: Cambridge University Press, 2003.

INSTITUTO DE PESQUISA ECONÔMICA APLICADA - Ipeadata. Dados comércio exterior. Disponível em: < http://www.ipeadata.gov.br> . Acesso em 6 abr. 2017. 
KHAN, S.; HAQ, I.U.; KHAN, D. An Empirical Analysis of Pakistan's Bilateral Trade: A Gravity Model Approach. The Romanian Economic Journal, n. 48, p. 103-120, 2013.

MCCALLUM, J. National Borders Matter: Canada-U.S. Regional Trade Patterns. The American Economic Review, v. 85, n. 3, p. 615-623, 1995.

MIRIAN, B. et al. An Analysis of International Raisin Trade: A Gravity Model Approach. In: AUSTRALIAN AGRICULTURAL AND RESOURCE ECONOMICS SOCIETY CONFERENCE, 57., 2013, Sydney.

OSENI, I. O. Exchange rate volatility and private consumption in Sub-Saharan African countries: A system-GMM dynamic panel analysis. Future Business Journal, v. 2, p. 103-115, 2016.

PAAS, T. Gravity Approach for Modeling Trade Flows between Estonia and the Main Trading Partners. University of Tartu - Faculty of Economics and Business Administration Working Paper Series, n. 4, 2000.

REIS, M. dos; AZEVEDO, A. F. Z. de; LELIS, M. T. C. Os efeitos do novo regionalismo sobre o comércio. Estudos Econômicos, v. 44, n. 2, p. 351-381, 2014.

SÁ PORTO, P. C de. Mercosur and Regional Development in Brasil: An Gravity Model Approach. Estudos Econômicos, v. 32, n. 1, p. 125-153, 2002.

SANTOS SILVA, J. M. C; TENREYRO, S. The Log of Gravity. The Review of Economics and Statistics, v. 88, n. 4, p. 641-658, 2006.

SAVAGE, I. R.; DEUTSCH, K. W. A Statistical Model of the Gross Analysis of Transaction Flows. Econometrica, v. 28, n. 3, p. 551-572, 1960.

TINBERGEN, J., A. Shaping the World Economy: Suggestions for an International Economic Policy. New York: Twentieth Century Fund, 1962.

WOOLDRIDGE, J. M. Econometric Analysis of Cross Section and Panel Data. Cambridge: MIT Press, 2002.

WORLD BANK - WB. World Development Indicator. Disponível em: < https://databank. worldbank.org/home.aspx>, Acesso em abr. 2017.

YANG, X. Estimating Distribution Costs with the Eaton-Kortum Model. Review of Development Economics, v.19. n. 3, 653-665, 2015.

YOTOV, Y. V. et al. An Advanced Guide to Trade Policy Analysis: The Structural Gravity Model. Geneva: World Trade Organization, 2016.

ZARZOSO, I. M.; LEHMANN, F. N. Augmented Gravity Model: An Empirical Application. Journal of Applied Economics, v. 8, n. 2, p. 291-316, 2003.

ZHU, H.; GU, H. China-US Border Effect of Agricultural Trade Using Gravity Model. In: LI, D.; ZHAO, C. Computer and Computing Technologies in Agriculture II. v. 2. New York: Springer, 
2008. p. 891-900. Disponível em: http://dl.ifip.org/db/conf/ifip12/ccta2008-2/ZhuG08.pdf. Acesso em: 29 jun. 2017.

\section{Autor correspondente:}

Júlio Vicente Cateia

Recebido em: 07/05/2019.

E-mail: juliocateia@yahoo.com.br

Aceito em: 21/11/2019.

\section{(cc) BY}

Este é um artigo de acesso aberto distribuído sob os termos da Creative Commons

Attribution CC-BY 4.0, que permite uso irrestrito, distribuição e reprodução em

qualquer meio, desde que o trabalho original seja devidamente citado. 